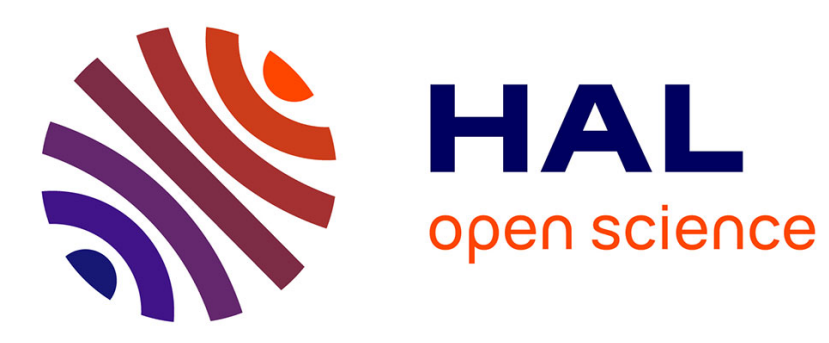

\title{
Depletion induced vesicle-to-micelle transition from self-assembled rod-coil diblock copolymers with spherical magnetic nanoparticles
}

Willy Agut, Daniel Taton, Annie Brûlet, Olivier Sandre, Sébastien Lecommandoux

\section{To cite this version:}

Willy Agut, Daniel Taton, Annie Brûlet, Olivier Sandre, Sébastien Lecommandoux. Depletion induced vesicle-to-micelle transition from self-assembled rod-coil diblock copolymers with spherical magnetic nanoparticles. Soft Matter, 2011, 7 (20), pp.9744-9750. 10.1039/c1sm05638g • hal-00668996

\section{HAL Id: hal-00668996 https://hal.science/hal-00668996}

Submitted on 3 Nov 2018

HAL is a multi-disciplinary open access archive for the deposit and dissemination of scientific research documents, whether they are published or not. The documents may come from teaching and research institutions in France or abroad, or from public or private research centers.
L'archive ouverte pluridisciplinaire HAL, est destinée au dépôt et à la diffusion de documents scientifiques de niveau recherche, publiés ou non, émanant des établissements d'enseignement et de recherche français ou étrangers, des laboratoires publics ou privés. 


\title{
Depletion Induced Vesicle-to-Micelle Transition from Self-Assembled Rod-Coil Diblock Copolymers with Spherical Magnetic Nanoparticles
}

\author{
Willy Agut, ${ }^{a, b}$ Daniel Taton, ${ }^{a, b}$ Annie Brûlet, ${ }^{\text {c,d }}$ Olivier Sandre, ${ }^{* a, b}$ and Sébastien Lecommandoux ${ }^{* a, b}$ \\ Received $10^{\text {th }}$ April 2011, Accepted $1^{\text {st }}$ June 2011 \\ ${ }_{5}$ DOI: 10.1039/C1SM05638G
}

This article describes the structural transition undergone by a vesicle forming diblock copolymer made of a hydrophobic poly( $\gamma$-benzyl-L-glutamate) sequence with helical secondary structure and of a hydrophilic poly[2-(dimethylamino)ethyl methacrylate] block when inserting hydrophobic iron oxide nanoparticles to impart magnetic properties in addition to $\mathrm{pH}$ - and temperature-responsiveness. Dispersed within the

10 hydrophobic rod-like polymer domains, the quasi-spherical particles experience depletion attraction, leading to microphase separation and finally to transition from vesicles to hybrid core-shell micelles. Such combination of self-assembly with excluded-volume effects, also present in living systems and giving rise to such a large structural diversity and functionality, can be integrated in materials science towards the design of original nanostructures.

\section{1. Introduction}

Most of the biological materials are soft with a structure and function resulting from self-assembly of multiple components differing by their molecular weight, size, shape, amphiphilicity and elasticity. In first approximation, such complex systems can 20 be analysed using soft matter physics approaches. ${ }^{1}$ Among others, rod-like molecules such as actin filaments or DNA are important in many biological systems where steric effects, due to the high local concentration resulting from compartmentalization, are known as "macromolecular crowding". 2 Because osmotic forces 25 are not restricted to particular components and length scales, the underlying principle of depletion interaction that is well-known in macromolecular science and physics is also applicable to biological systems. While the understanding of depletion forces in bi-modal spherical colloids ${ }^{3}$ and colloid-polymer systems ${ }^{4}$ is 30 advanced, less is known when colloidal rods are used as depletion agent.

Amphiphilic block copolymers are known to self-assemble into well-defined structures depending on their hydrophilic-tohydrophobic weight ratio. In particular, a hydrophilic fraction in a 35 range of $30-40 \%$ leads to the formation of vesicles referred to as polymersomes. ${ }^{5}$ Recently, we reported the synthesis of block copolymers featuring, on the one hand, a rigid poly $(\gamma$-benzyl-Lglutamate) (PBLG) polypeptide sequence exhibiting $\alpha$-helical secondary structure and, on the other hand, a hydrophilic block 40 poly[2-(dimethylamino)ethyl methacrylate] (PDMAEMA), which displays a dual responsiveness to both $\mathrm{pH}\left(\mathrm{pK}_{\mathrm{a}}=7.7\right)$ and temperature $\left(\mathrm{LCST}=39^{\circ} \mathrm{C}\right){ }^{6}$ More generally, the propensity of amphiphilic copolymers based on PBLG blocks to self-assemble into polymersomes is well-documented. ${ }^{7}$ The formation of 45 polymer vesicles is indeed facilitated by the two-dimensional stacking of rod-like PBLG helices into planar membranes.

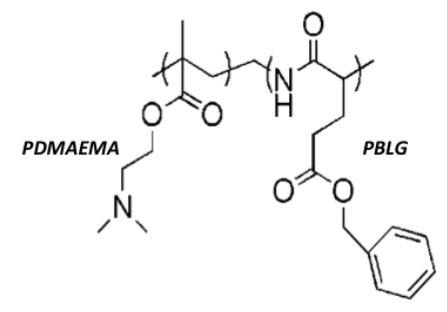

Scheme 1 Amphiphilic diblock copolymer made of a hydrophilic thermosenstitive block (PDMAEMA) and a hydrophobic rod-like 50 polypeptide block (PBLG)

Ultra-small superparamagnetic iron oxide particles (USPIO) are individual nanoparticles made of either $\gamma-\mathrm{Fe}_{2} \mathrm{O}_{3}$ or $\mathrm{Fe}_{3} \mathrm{O}_{4}$ used as negative contrast-enhancing agents in magnetic resonance imaging under the brand names of Sinerem or Ferumoxtran. To 55 achieve improved properties (proton relaxivity in MRI, biodistribution, specific absorption rate in radio-frequency hypethermia...), SPIO particles which can be viewed as controlled clusters of USPIOs of size typically below $200 \mathrm{~nm}$ are generally preferred to USPIOs. ${ }^{8}$ Relatively well-controlled clusters are 60 obtained by using strong adsorbing hydrophilic homopolymers such as Dextran, ${ }^{9}$ or with copolymers forming micelles, ${ }^{10}$ coacervates $^{11}$ or microgels. ${ }^{12}$ Formation of polymersomes confining USPIOs between the leaflets of their hydrophobic membrane was reported in the case of a few amphiphilic 65 copolymers, namely poly(butadiene)- $b$-poly(L-glutamic acid) (PB- $b$-PGA), ${ }^{13}$ poly(isoprene)- $b$-poly(ethylene oxide) (PI- $b$ PEO), ${ }^{14}$ poly(styrene)- $b$-poly(acrylic acid) (PS- $b$-PAA), ${ }^{15}$ and poly(trimethylene carbonate)- $b$-poly(L-glutamic acid) (PTMC- $b$ PGA). ${ }^{16}$

70 In this paper, we report on the self-assembly of amphiphilic block copolymers comprising a rod-like segment in the presence of quasi-spherical nanoparticles. We aim at demonstrating that 
depletion forces can strongly influence the self-assembly properties in such binary systems and can be presented as an original trigger to drive the equilibrium structures.

\section{Experimental}

\section{${ }_{5}$ A. Synthesis and coupling of polymer blocks}

As described in a previous report, ${ }^{17}$ the poly $(\gamma$-benzyl-Lglutamate)- $b$-poly[2-(dimethylamino)ethyl methacrylate] (PBLG$b$-PDMAEMA) block copolymer was synthesized by the Huisgen's 1,3-dipolar cycloaddition ("click chemistry") from the ${ }_{10}$ PBLG and PDMAEMA homopolymers containing azide and alkyne antagonist functionalities.

\section{B. Synthesis and coating of the magnetic nanoparticles}

USPIOs made of $\gamma-\mathrm{Fe}_{2} \mathrm{O}_{3}$ iron oxide were synthesized by alkaline co-precipitation of iron salts in water. ${ }^{18}$ Using a size sorting ${ }^{15}$ procedure, ${ }^{19}$ the distribution of diameters was narrowed so as to be described by a Log-normal distribution of median value $d_{0}=6.3$ $\mathrm{nm}$ and width $\sigma=0.22$ as measured by magnetometry (Fig. S1 in SI). Then the USPIOs were coated by an anionic surfactants mixture of alkylethoxyphenol mono- and diesters of phosphoric 20 acid (Beycostat NB09, CECA, Arkema group), ${ }^{20}$ enabling a perfect dispersed state in dichloromethane $\left(R_{\mathrm{H}}=9.4 \mathrm{~nm}\right)$.

\section{Self-assembly processes}

\section{i. Direct dissolution}

The hydrophilic-lipophilic balance allowed a direct dissolution of 25 the copolymer $(1 \mathrm{~g} / \mathrm{L})$ by simple stirring for $48 \mathrm{~h}$ in distilled water $(\mathrm{pH} 6.5)$ at $25^{\circ} \mathrm{C}$ or $105^{\circ} \mathrm{C}$ under reflux ). ${ }^{21}$

\section{ii. Solvent injection or "nano-precipitation"}

Unlike with molecular surfactants readily forming mesophases at 30 thermodynamic equilibrium when poured into water, the selfassembly of amphiphilic copolymers can be hampered by kinetic issues when using glassy or semi-crystalline blocks such as in the PDMAEMA- $b$-PBLG used here. In that case, a solvent injection (displacement) method is generally preferred to direct dissolution. 35 An intermediate solvent is used to solubilise the copolymer while being miscible with water. ${ }^{22}$ By tuning the mixing conditions, the inter-diffusion kinetics between the two solvents is controlled, which maintains the chains in a dynamical state all along the selfassembly process, improving the control of the sizes of the 40 resulting nanoparticles. The PDMAEMA- $b$-PBLG copolymer was dissolved at $10 \mathrm{~g} / \mathrm{L}$ in THF or in DMSO. Then an aqueous solution buffered at $\mathrm{pH} 6.5$ was added at constant flow rate $(0.1$ $\mathrm{mL} / \mathrm{mn}$ with a syringe pump) under vigorous stirring (400 rpm with a magnetic bar) until reaching a volumetric ratio 9/1 of 45 water to solvent and a copolymer concentration of $1 \mathrm{~g} / \mathrm{L}$. The organic solvent was removed from the suspension by extensive dialysis in water ( $\mathrm{pH}$ 6.5), except for the samples used in SANS experiments to avoid the use of a large volume of $\mathrm{D}_{2} \mathrm{O}$. For the preparation of hybrid objects, a dispersion of USPIOs at $95 \mathrm{~g} / \mathrm{L}$ in ${ }_{50} \mathrm{CH}_{2} \mathrm{Cl}_{2}$ was added to the organic solution in DMSO at a feed weight ratio of 10 or $20 \mathrm{wt}$. \% relatively to the copolymer $(0.1$ or $0.2 \mathrm{~g} / \mathrm{L}$ ). After rapid evaporation of $\mathrm{CH}_{2} \mathrm{Cl}_{2}$, the nanoprecipitation was conducted as described before.

\section{Methods}

55 Size exclusion chromatography (SEC) was used to determine molar masses (calibrated with linear PS standards) and their dispersities in $\mathrm{DMF}+\mathrm{LiBr}(1 \mathrm{~g} / \mathrm{L})$ at $60^{\circ} \mathrm{C}(0.8 \mathrm{~mL} / \mathrm{min})$ with a Waters system (Alliance GPCV2000) equipped with three TSK columns $(7.8 \times 30 \mathrm{~cm}, 5 \mu \mathrm{m}$ of respective pores' sizes 250,1500 60 and $10000 \AA$ ) and a differential refractometer (Jasco, RI-1530).

NMR ${ }^{1} \mathrm{H}$ and ${ }^{13} \mathrm{C}$ spectra were done on a $400 \mathrm{MHz}$ Bruker AC400 spectrometer.

Differential Scanning Calorimetry (DSC) curves were acquired on a Q100 DSC setup (TA Inst.) under helium flow. Temperature 65 ramps between $-50^{\circ} \mathrm{C}$ and $150^{\circ} \mathrm{C}$ were done at $10^{\circ} \mathrm{C} / \mathrm{min}$.

Transmission electronic microscopy (TEM) micrographs were obtained on a Hitachi H7650 microscope operating at $80 \mathrm{kV}$ and grabbed with a Gatan Orius 11 Mpixels camera. Samples were prepared by spraying aqueous solutions at $1 \mathrm{mg} / \mathrm{mL}$ with a home70 made nitrogen nebulizer on carbon films of 400 mesh grids and then dried under air at room temperature.

Dynamical Light Scattering was performed using an ALV Laser goniometer, which consisted of a $35 \mathrm{~mW}$ HeNe linear polarized laser with a wavelength of $632.8 \mathrm{~nm}$ and an ALV-5000/EPP 75 Multiple Tau Digital correlator with 125 ns initial sampling time. DLS measurements were either mono-angle $\left(90^{\circ}\right)$ or multi-angle (ranging from $50^{\circ} \mathrm{C}$ to $130^{\circ}$ ). Aliquots of samples $(1 \mathrm{~mL}$ in a 10 $\mathrm{mm}$ diameter cylindrical glass cell) were immersed in a filtered toluene bath regulated at $25{ }^{\circ} \mathrm{C}$. The data were acquired with the 80 ALV-Correlator Control software with a counting time between 60 and $300 \mathrm{~s}$ depending on the angle. The intensity correlograms were treated by the CONTIN fit to obtain the distribution of the correlation times and by the cumulants fit to yield the $z$-average hydrodynamic radius $\left(R_{\mathrm{H}}\right)$ through Stokes-Einstein's formula and 85 the polydispersity index (PDI) from the ratio of the $2^{\text {nd }}$ order cumulant divided by the square of the $1^{\text {st }}$ order one.

Small Angle Neutron Scattering measurements were performed on the PACE spectrometer of the Laboratoire Léon Brillouin (CEA-Saclay, France) equipped with an isotropic $\mathrm{BF}_{3}$ detector 90 made of 30 concentring rings of $1 \mathrm{~cm}$ width each. We used two configurations: the first one with a sample-to-detector distance of $D=4.57 \mathrm{~m}$ and a neutron wavelength of $\lambda=17 \AA$ to cover a $q$ range of $3.2 \times 10^{-3}-2.6 \times 10^{-2} \AA^{-1}$; the second one with $D=2.87 \mathrm{~m}$ and $\lambda=6 \AA$ to cover a $q$ range of $1.1 \times 10^{-2}-0.1 \AA^{-1}$.

95 The neutron scattering-length density (SLD) of the hydrophilic blocks $\rho^{\text {PDMAEMA }}=8 \times 10^{9} \mathrm{~cm}^{-2}$ is comparable to the magnetic SLD of the USPIOs $\rho_{\text {mag }}{ }^{\mathrm{Fe} 2 \mathrm{O} 3}=9 \times 10^{9} \mathrm{~cm}^{-2}$. Both of them are far away from the nuclear SLDs of the USPIOs $\rho_{\text {nucl }} \mathrm{Fe}^{\mathrm{O} 3}=7 \times 10^{10} \mathrm{~cm}^{-2}$ and of the hydrophobic blocks of the copolymer $\rho^{\text {PBLG }}=2.3 \times 10^{10} \mathrm{~cm}^{-2}$. 100 In pure $\mathrm{H}_{2} \mathrm{O}\left(\rho^{\mathrm{H} 2 \mathrm{O}}=-0.56 \times 10^{9} \mathrm{~cm}^{-2}\right)$, one observes mainly the nuclear scattering of USPIOs $\left(\Delta \rho^{\mathrm{Fe} 2 \mathrm{O} 3}=7.5 \times 10^{10} \mathrm{~cm}^{-2}\right)$ but also in a reduced way (i.e. 7 times lower contrast value $\Delta \rho^{2}$ ) of the hydrophobic core of the copolymer $\left(\Delta \rho^{\mathrm{PBLG}}=2.8 \times 10^{10} \mathrm{~cm}^{-2}\right)$. The solvent of nanoprecipitated samples was a 9:1 mixture of $\mathrm{D}_{2} \mathrm{O}$ 05 and deuterated DMSO $\left(\rho^{\text {D2O/DMSO-d6 }}=6.2 \times 10^{10} \mathrm{~cm}^{-2}\right)$ leading to a low contrast $\Delta \rho^{\mathrm{Fe} 2 \mathrm{O} 3}=8.1 \times 10^{9} \mathrm{~cm}^{-2}$ with $\gamma-\mathrm{Fe}_{2} \mathrm{O}_{3}$ and high contrasts with both the polymer blocks $\Delta \rho^{\mathrm{PBLG}}=3.9 \times 10^{10} \mathrm{~cm}^{-2}$ and $\Delta \rho^{\text {PDMAEMA }}=5.4 \times 10^{10}$. To minimize the incoherent scattering, the SANS measurements were done in quartz cuvettes of thickness 110 respectively $5 \mathrm{~mm}$ for $\mathrm{D}_{2} \mathrm{O} / \mathrm{DMSO}-\mathrm{d}_{6}$ and $1 \mathrm{~mm}$ for $\mathrm{H}_{2} \mathrm{O}$. All the scattered intensity curves were normalized by the incoherent signal delivered by a $1 \mathrm{~mm}$ gap water sample in order to account 
for the efficiency of the detector cells and the incoherent backgrounds of the solvents were subtracted. Absolute values of the scattering intensity $I(q)$ in $\mathrm{cm}^{-1}$ were obtained from the direct determination of the number of neutrons in the incident beam and 5 the detector cell solid angle. ${ }^{23}$

\section{Results}

\section{A. Characterisation of the copolymer}

Table 1 Molecular characteristics of the PDMAEMA- $b$-PBLG copolymer

\begin{tabular}{|c|c|c|c|c|}
\hline Sample & $M_{\mathrm{n}, \mathrm{PDMAEMA}}{ }^{\mathrm{a}}$ & $M_{\mathrm{n}, \mathrm{PBLG}}{ }^{\mathrm{a}}$ & $M_{\mathrm{n}, \text { copolymer }}^{\mathrm{a}}$ & $\mathrm{PDI}^{\mathrm{a}}$ \\
\hline PDMAEMA $_{85}-b-\mathrm{PBLG}_{4}$ & 13300 & 9000 & 22300 & 1.17 \\
\hline
\end{tabular}

The characterisation of the copolymer by NMR and SEC reported in Table 1 led to a hydrophobic weight fraction $f_{\mathrm{PBLG}}=40 \%$. The glass transition temperatures of both homopolymers and of the copolymer assessed by DSC all ranged between 10 and $20^{\circ} \mathrm{C}$ 15 (Fig. S2 in SI). Moreover, a melting transition (from crystal to liquid-crystal state) was detected around $100^{\circ} \mathrm{C}$ and ascribed to the irreversible conformational change from $7 / 2$ to $18 / 5$ helices of the PBLG helices. ${ }^{24}$ These characteristic transition temperatures in bulk are important to tune the self-assembling properties in 20 solution.

\section{B. Pure block copolymer self-assembly}

\section{i. Direct dissolution}

Table 2 Hydrodynamic radii $\left(R_{\mathrm{H}}\right)$ and polydispersity indexes (PDI) 25 obtained by direct dissolution of PDMAEMA ${ }_{85}-b-\mathrm{PBLG}_{41}$ at $1 \mathrm{~g} / \mathrm{L}$ at several values of temperature and $\mathrm{pH}$.

\begin{tabular}{cccccc}
$\mathrm{T}^{\mathrm{a}}$ & $\mathrm{T}^{\mathrm{b}}$ & $\mathrm{pH}^{a}$ & $\mathrm{pH}^{b}$ & $R_{\mathrm{H}}$ & PDI \\
$25^{\circ} \mathrm{C}$ & $25^{\circ} \mathrm{C}$ & 6.5 & 6.5 & 107 & 0.43 \\
$105^{\circ} \mathrm{C}$ & $25^{\circ} \mathrm{C}$ & 6.5 & 6.5 & 58 & 0.44 \\
$105^{\circ} \mathrm{C}$ & $25^{\circ} \mathrm{C}$ & 2.5 & 2.5 & 46 & 0.19 \\
$105^{\circ} \mathrm{C}$ & $25^{\circ} \mathrm{C}$ & 2.5 & 7.2 & 46 & 0.31 \\
$105^{\circ} \mathrm{C}$ & $25^{\circ} \mathrm{C}$ & 2.5 & 11.4 & 43 & 0.43 \\
\multicolumn{5}{c}{ during dissolution; ${ }^{b}$ during DLS measurement. } \\
\hline
\end{tabular}

The hydrodynamic radius $R_{\mathrm{H}}$ of the objects formed by direct dissolution (Fig. 1 and Table 2) in water at pH 6.5 decreased from 30 $107 \mathrm{~nm}$ at $25^{\circ} \mathrm{C}$ (just above glass transition of the copolymer) to $58 \mathrm{~nm}$ at $105^{\circ} \mathrm{C}$ (just above the melting temperature of PBLG). However, size distributions remained very large ( $\mathrm{PDI}=0.43$ ). An attempt was made to narrow the size distribution by saturating the positive charge of PDMAEMA during dissolution at $\mathrm{pH} 2.5$ well 35 below the $\mathrm{pK}_{\mathrm{a}}=7.7$ of the ammonium moiety, promoting electrostatic repulsions between the objects. This enabled to decrease both $R_{\mathrm{H}}$ and PDI down to $46 \mathrm{~nm}$ and 0.19 respectively. However, the PDI returned to high values by progressively rising up the $\mathrm{pH}$, presumably due to the apparition of a slight portion of 40 aggregates. As a result, due to the intrinsic rigidity of PBLG and its crystalline behaviour below $100^{\circ} \mathrm{C}$, the direct self-assembly of the copolymer leads to unstable and poorly defined structures.
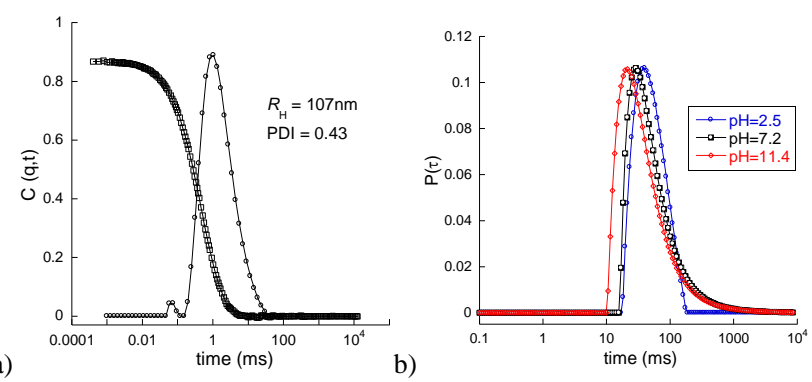

Fig. 1 DLS correlograms at a scattering angle of $90^{\circ}$ and distributions of 45 the correlation times $P(\tau)$ for PDMAEMA ${ }_{85}-b-\mathrm{PBLG}_{41}$ directly dispersed in water at $25^{\circ} \mathrm{C}$ and $\mathrm{pH} 6.5$ (a) and at $105^{\circ} \mathrm{C}$ and varying $\mathrm{pH}$ (b).

\section{ii. Solvent injection or "nano-precipitation"}

In order to better control the self-assembly process, we implemented the nanoprecipitation method using two different 50 intermediate solvents.
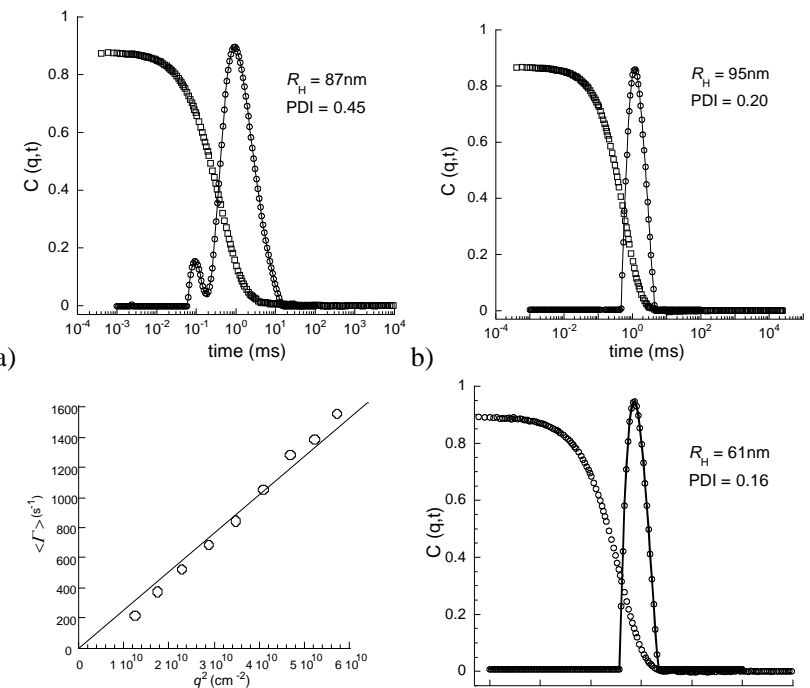

c)
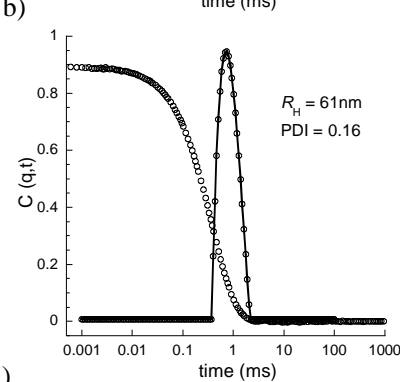

Fig. 2 DLS correlogram at a scattering angle of $90^{\circ}$ and distribution of the correlation times for PDMAEMA ${ }_{85}-b-\mathrm{PBLG}_{41}$ nano-precipitated objects

55 for a) water-to-THF injection; b) water-to-DMSO injection; c) multiangle DLS illustrating the low PDI with water-to-DMSO injection by the

perfect linearity of the mean decay rate $\langle\Gamma\rangle$ with the square of the scattering vector, $q^{2}$; d) DLS correlogram at $90^{\circ}$ and distribution of the correlation times for hybrid objects made of PDMAEMA ${ }_{85}-b-\mathrm{PBLG}_{41}$ and $60 \gamma-\mathrm{Fe}_{2} \mathrm{O}_{3}$ USPIOs (10 wt. \%) prepared by water-to-DMSO injection. The $\mathrm{pH}$ value was 6.5 for all the preparations.

In the case of water-to-THF injection (Fig. 2a), a bimodal distribution of relaxation times associated to large size dispersity was ascribed to the rather poor solubility of PBLG helices in ${ }_{65} \mathrm{THF}^{25}$ Larger sizes were also found when this solvent was used to prepare PTMC- $b$-PGA polymersomes by nanoprecipitation. ${ }^{26}$ On the contrary, water-to-DMSO injection leads to objects of same order of magnitude of size $\left(R_{\mathrm{H}}=95 \mathrm{~nm}\right)$ than direct dissolution, but with a much lower $\mathrm{PDI}=0.20$ (Fig. 2b). The 70 variation of the scattering angle of the goniometer between $50^{\circ}$ and $130^{\circ}$ led to a perfect linearity of the $1^{\text {st }}$ order cumulant of the correlogram ( $z$-average decay rate) $v s$. the square of the scattering vector (Fig. 2c), indicating the presence of isotropic scatterers with narrow size dispersity. To get an insight of the structure of 75 the nanoparticles at a much lower scale, we used much higher 
resolution techniques such as TEM (Fig. 3) and SANS (Fig. 4).

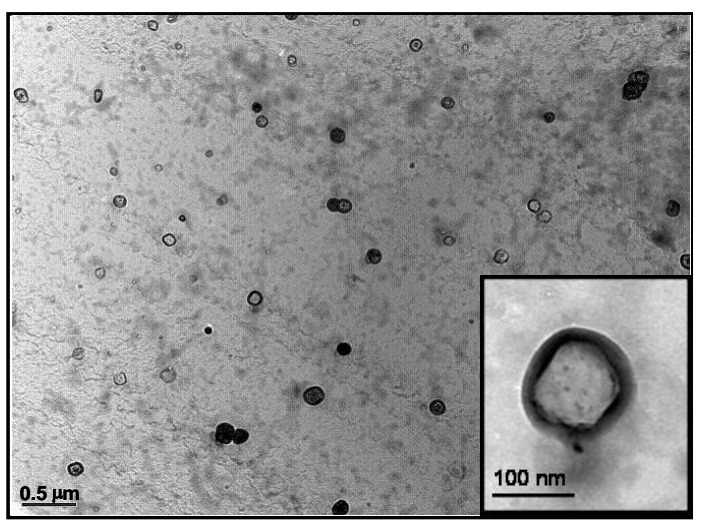

Fig. 3 TEM pictures of PDMAEMA ${ }_{85}-b-\mathrm{PBLG}_{41}$ vesicles prepared by water-to-DMSO nanoprecipitation at two magnifications (see scale bars).

5 The TEM pictures clearly showed hollow spheres with diameters ranging from 80 to $160 \mathrm{~nm}$ with an average around 120 $\mathrm{nm}$. A close-up view at a larger magnification enabled to measure a membrane thickness of about $20 \pm 5 \mathrm{~nm}$.

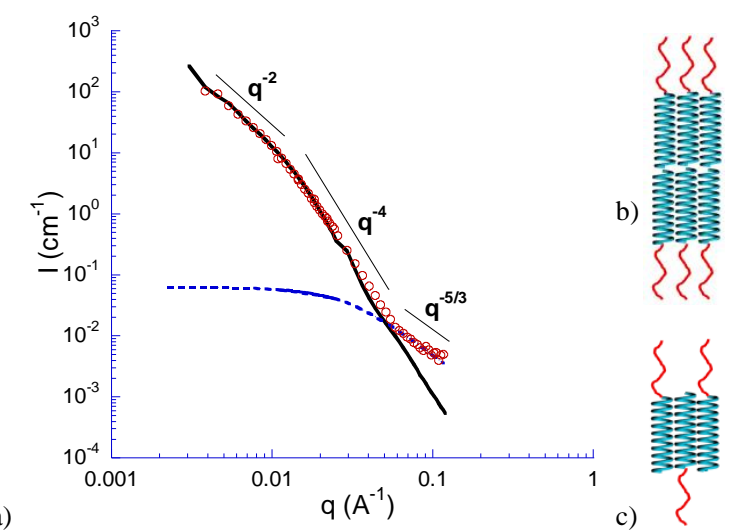

10 Fig. 4 a) SANS curve of PDMAEMA ${ }_{85}-b-\mathrm{PBLG}_{41}$ vesicles prepared by water-to-DMSO nanoprecipitation. In $\mathrm{D}_{2} \mathrm{O} / \mathrm{DMSO}-\mathrm{d}_{6}$, the scattering contrast comes from both polymer blocks. The solid curve represents the form factor of vesicles of median radius $R_{0}=90 \mathrm{~nm}\left(\sigma_{\text {radius }}=0.2\right)$ and shell thickness $\delta_{0}=20 \mathrm{~nm}\left(\sigma_{\text {thickness }}=0.3\right)$; b) Sketch for a PDMAEMA ${ }_{85}-b$ -

$15 \mathrm{PBLG}_{41}$ bilayer; $\mathrm{c}$ ) Sketch of membrane in case of interdigitated helices.

The experimental SANS intensity exhibit several scaling law behaviours in the successive ranges of scattering vector. At low $q$, the intensity does not saturate because the gyration radius is too large to be accessible in the SANS $q$-range. In the intermediate $q$ 20 regime, the intensity scaling law as $q^{-2}$ is typical of flat membranes' structure of large vesicles. Then the Porod's regime varying like $q^{-4}$ turns to $q^{-5 / 3}$ at high $q$ presumably due to a rough interface of objects covered with Gaussian chains. The form factor of a shell of internal and external radii $R-\delta / 2$ and $R+\delta / 2$ 25 was convolved with two Log-normal distributions of the radius and thickness (median values $R_{0}$ and $\delta_{0}$, widths $\sigma_{\text {radius }}$ and $\sigma_{\text {thickness }}$ ) using appropriate averaging of polydispersity. ${ }^{27}$ The median thickness $\delta_{0}=20 \mathrm{~nm}$ of the fitted curve well compares to the TEM pictures. As described in the experimental part, the 30 neutron SLD contrasts of PDMAEMA and PBLG with $\mathrm{D}_{2} \mathrm{O} / \mathrm{DMSO}-\mathrm{d}_{6}$ are comparable. Therefore the shell fit reflects the total thickness of the membrane. PBLG chains in helical conformation can be modelled by cylindrical rods of diameter
$1.25 \mathrm{~nm}$ and of length $0.15 \mathrm{~nm}$ per $\gamma$-benzyl-L-glutamate 35 monomer, ${ }^{28}$ i.e. $6.15 \mathrm{~nm}$ for a degree of polymerization of 41 . Thus we can imagine two extreme possibilities for the membrane formation with $\mathrm{PDMAEMA}_{85}-b-\mathrm{PBLG}_{41}$ : either the copolymers form a bilayer with a hydrophobic thickness of $12 \mathrm{~nm}$ covered on both sides by a compact layer around $4 \mathrm{~nm}$ of hydrophilic coils 40 (Fig. 4b), or the PBLG helices are interdigitated in a narrower layer about $6 \mathrm{~nm}$ enabling the hydrophilic chains to be in a much more stretched conformation around $7 \mathrm{~nm}$ (Fig. 4c). The latter situation is likely in better agreement with the vesicle geometry for the charged PDMAEMA chains in a brush regime due to 45 confinement at a locally planar interface

\section{Hybrid self-assembled structures}

Compared to previous case of "blank" pure copolymer particles, the DLS results for hybrids at $10 \mathrm{wt}$. \% shown in Fig. $2 \mathrm{~d}$ were rather striking due to a lower hydrodynamic size $\left(R_{\mathrm{H}}=61 \mathrm{~nm}\right)$ and 50 a narrower size distribution $(\mathrm{PDI}=0.16)$. This result was supported by observation of the TEM images, showing much more compact objects (Fig. 5 vs. Fig. 3). However, one should be aware of artefacts due to the projection effect of TEM onto a planar surface and to the lower electron scattering density of the 55 copolymer compared to $\gamma-\mathrm{Fe}_{2} \mathrm{O}_{3}$. Therefore SANS measurements were also necessary to decipher the exact arrangement of USPIOs within the hybrid particles.

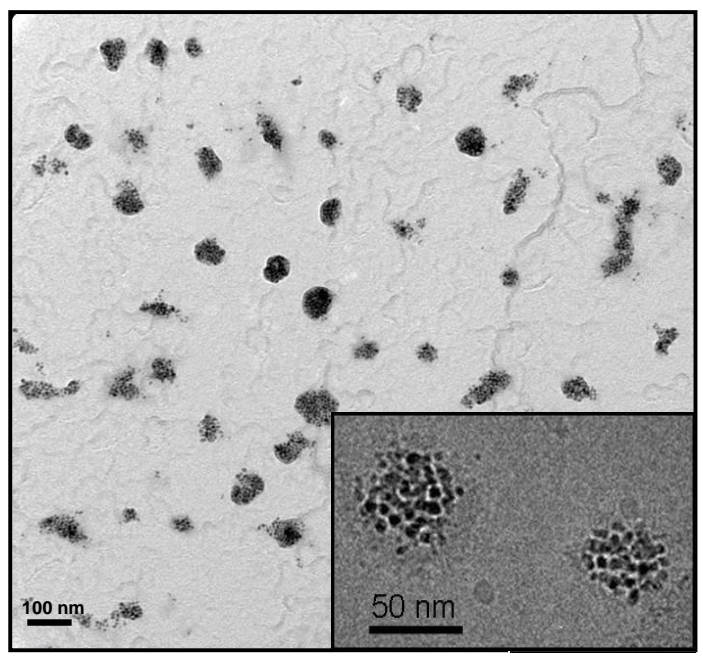

Fig. 5 TEM pictures of PDMAEMA $A_{85}-b-\mathrm{PBLG}_{41} / \gamma-\mathrm{Fe}_{2} \mathrm{O}_{3}(10$ wt. \%) 60 hybrid nanoparticles prepared by water-to-DMSO injection at two magnifications (see scale bars).

Unlike previous SANS measurements with pure copolymer particles in deuterated solvents mixture, the solvent used for hybrid particles was light water in order to benefit from the large 65 neutron SLD contrast of iron oxide relatively to $\mathrm{H}_{2} \mathrm{O}$ (see part 2 . D. Methods). A centrifugation step was also applied to increase the concentration and thus the SANS intensity. For two weight ratios of $\gamma-\mathrm{Fe}_{2} \mathrm{O}_{3}$ to copolymer, the curves plotted on Fig. 6 were well adjusted by the form factor of filled polydisperse spheres of 70 radii with a Log-normal distribution law of median $R_{0}=18 \mathrm{~nm}$ and width $\sigma=0.25$. The scaling law as $q^{-2}$ typical of the membrane of large vesicles was clearly not observed here, attesting a structural change when the copolymer was self-assembled in the presence of the inorganic nanoparticles with a hydrophobic coating. While 
inaccessible by SANS for the pure copolymer vesicles, the radius of gyration measured by Guinier's plots was 19.9 and $19.2 \mathrm{~nm}$ respectively for 10 and $20 \mathrm{wt}$ \% hybrids.
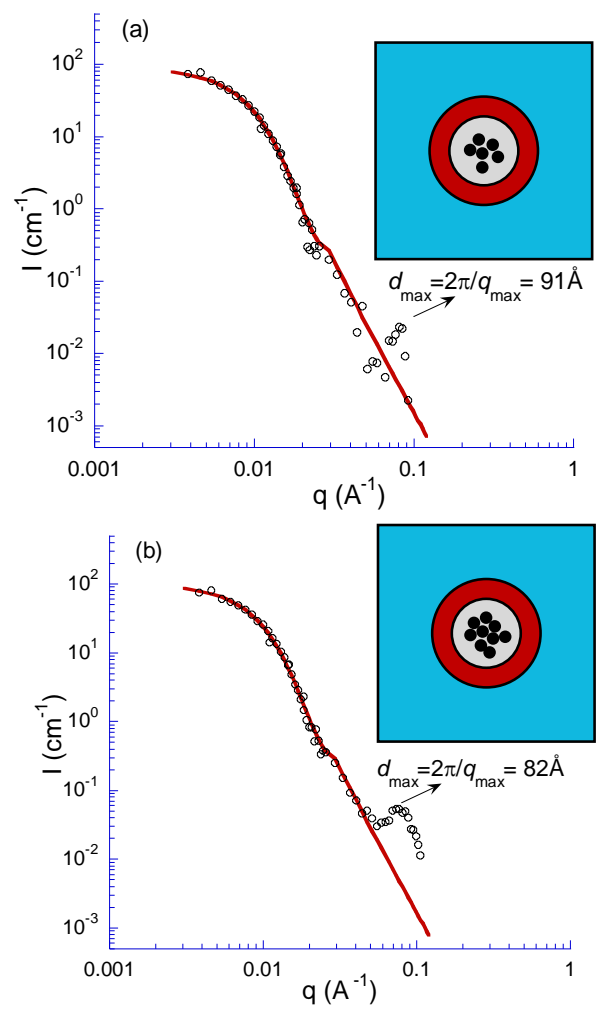

Fig. 6 SANS curve of PDMAEMA $\mathrm{P}_{85}-b-\mathrm{PBLG}_{41} / \gamma-\mathrm{Fe}_{2} \mathrm{O}_{3}$ hybrid particles prepared by water-to-DMSO injection at (a) 10 and (b) $20 \mathrm{wt}$. \%. In both cases, the solid curve represents the form factor of polydisperse filled spheres with a Log-normal distribution law of radii of median $R_{0}=18 \mathrm{~nm}$ 10 and width $\sigma=0.25$. The sketches in insets represent the nanoscale structure of core-shell micelles with the USPIOs (in black) closely packed in PBLG hydrophobic cores (in grey) wrapped by a hydrated PDMAEMA shell not contributing to the SANS contrast in $\mathrm{H}_{2} \mathrm{O}$ (in red).

In addition, the curves clearly displayed a structure peak at 15 large $q$ values. Its maximum was measured at $q_{\max }$ around 0.069 $\AA^{-1}$ for $10 \mathrm{wt}$. $\%$ and $0.076 \AA^{-1}$ for $20 \mathrm{wt}$. \%, corresponding to a strong correlation of centre-to-centre distances $d_{\max }=2 \pi / q_{\max }$ around 9.1 and $8.2 \mathrm{~nm}$ respectively. Considering the sizes of the $\gamma-\mathrm{Fe}_{2} \mathrm{O}_{3}$ cores (Log-normal law of $d_{0}=6.3 \mathrm{~nm}$ and width $\sigma=0.22$ ), 20 these USPIOs were closely packed inside the objects as observed on Fig. 5 and sketched in the insets of Fig. 6. More precisely, we can calculate that inside the objects, USPIOs have a local volume fraction $\Phi_{\text {local }}=\pi / 6\left(d_{\mathrm{w}} / d_{\max }\right)^{3}$ where $d_{\mathrm{w}}$ is the weight averaged diameter of the Log-normal law, given by $d_{\mathrm{w}}=d_{0} \exp \left(7 \sigma^{2} / 2\right)$. ${ }_{25}$ Numerically, we found $d_{\mathrm{w}}=7.5 \mathrm{~nm}, \Phi_{\text {local }}=29 \%$ for $10 \mathrm{wt}$. $\%$ and $\Phi_{\text {local }}=40 \%$ for $20 \mathrm{wt}$. $\%$. These values are much higher than the average volume fractions if the USPIOs were homogeneously distributed in the hydrophobic part of the hybrids: from the mass density of PBLG $\left(1.44 \mathrm{~g} / \mathrm{cm}^{3}\right)$ and $\gamma-\mathrm{Fe}_{2} \mathrm{O}_{3}\left(5.1 \mathrm{~g} / \mathrm{cm}^{3}\right)$ and the 30 weight fraction of PBLG (60\%) in PDMAEMA ${ }_{85}-b-\mathrm{PBLG}_{41}$, we calculate $\Phi_{\mathrm{ave}}=5 \%$ for $10 \mathrm{wt}$. $\%$ and $\Phi_{\mathrm{ave}}=10.5 \%$ for $20 \mathrm{wt}$. $\%$. Another calculation aims at estimating the number of USPIOs per object in each case according to $N_{\text {USPIO }}=\Phi_{\text {local }}\left(d_{\text {core }} / d_{\mathrm{w}}\right)^{3}$, where $d_{\text {core }}$ stands for the diameter of hydrophobic core sketched 35 in grey on Fig. 6. As only $\gamma-\mathrm{Fe}_{2} \mathrm{O}_{3}$ and PBLG contribute to the neutron SLD contrast (but not the hydrated shell of PDMAEMA), we calculate a core size $d_{\text {core }}=2 R_{0} \exp \left(7 \sigma^{2} / 2\right)=44.8 \mathrm{~nm}$ using $R_{0}=18 \mathrm{~nm}$ and $\sigma=0.25$ as used to fit the SANS curves. Therefore the estimates of average numbers of clustered USPIOs are 40 $N_{\text {USPIO }}=62$ for 10 wt. $\%$ and $N_{\text {USPIO }}=85$ for 20 wt. $\%$.

\section{Discussion}

Thermally induced morphology transition from micelles to vesicles has been recently described for a diblock copolymer. ${ }^{29} \mathrm{~A}$ bilayer-to-micelle transition by incorporation of USIPOs has been ${ }_{45}$ recently described with a PS- $b$-PAA diblock copolymer. ${ }^{15}$ In the latter case, the volume fraction at the onset of the transition was located around $12 \%$, whereas the fraction of micelles progressively increased for larger $\Phi$. However, true magnetopolymersomes could be obtained with up to $35.8 \mathrm{wt}$. \% of oleic 50 acid coated magnetite USPIOs in PS- $b$-PAA. For PI- $b$-PEO, a phenomenon of bilayer bridging by the USPIOs was observed when the weight ratio of iron oxide exceeded $20-30$ wt. $\%{ }^{14}$ Nevertheless, the stable structure still consisted in polymer vesicles, in spite of their multi-lamellar structure. In the case of ${ }_{55}$ PTMC- $b$-PGA, magnetic membranes were observed up to $70 \mathrm{wt}$. $\%,{ }^{16}$ while the limit was pushed further than twice the polymer content with a soft elastomeric hydrophobic block such as in PB$b$-PGA. ${ }^{13}$ On the contrary, this study shows that the PDMAEMA $_{85}-b-$ PBLG $_{41}$ vesicle self-assembling structure cannot 60 even withstand to a volume fraction as low as $\Phi_{\text {ave }}=5 \%$ of USPIOs in the PBLG blocks. This phenomenon is reminiscent of the phase behaviour of USPIOs of same sizes, nature and surfactant coating in the nematic thermotropic liquid crystal 4pentyl-4'-cyanobiphenyle: ${ }^{20}$ while the inorganic nanoparticles are 65 properly dispersed in the isotropic phase (up to $\Phi=0.83 \%$ at least), they are expelled towards the defect lines as soon as temperature is lowered below the nematic-to-isotropic transition, even at a fraction as small as $\Phi=0.08 \%$. This analogy is worth mentioning since PBLG is known itself to exhibit lyotropic liquid 70 crystal phases ${ }^{28}$ and to have a rod-like conformation in such solvents. ${ }^{30}$ Thus in the following, we present a discussion in the framework of the complex phase behaviour of binary mixtures of spherical and rod-like particles driven by the depletion interaction. $^{31}$

75 Entropic in nature, this interaction originates from osmotic pressure forces acting on hard spheres immersed in a suspension of cylindrical rods, the volume excluded to rods being described by a depletion layer surrounding the spheres. Referring to a model in the literature, ${ }^{32}$ we calculate the attractive depletion 80 potential acting between two hard spheres with their surfaces at a distance $H: \quad U \mathrm{depl}(H) / k_{\mathrm{B}} T=\Phi_{\text {rods }}\left(L R / D^{2}\right) K_{1}(H / L)$. Here the $\alpha$-helices of PBLG are modelled as rigid cylinders of length $L=6.15 \mathrm{~nm}$ and diameter $D=1.25 \mathrm{~nm}$, thus of aspect ratio $L / D \approx 5$. The USPIOs are quasi-spherical nanoparticles with a typical 85 radius $R=d_{\mathrm{w}} / 2=3.75 \mathrm{~nm}$. The binary mixture is thus characterized by a size ratio of rod length to sphere radius $L / R \approx 1.64$. The value of the potential when the spheres are at close contact $(H=0)$ is given by the value of the function $K_{1}(0)$ calculated numerically in this reference and leading to $K_{1}(0)=-0.219 .{ }^{\ddagger}$ sing $L R / D^{2} \approx 14.8$ in 90 the present geometry and $\Phi_{\mathrm{rods}}=1-\Phi_{\mathrm{ave}}$ in the hydrophobic cores, we calculate $U_{\mathrm{depl}}(H=0) / k_{\mathrm{B}} T \approx-3.1$ and -2.9 respectively for 10 and 20 wt. $\%$ of USPIOs in the copolymer. Therefore the depletion 
attraction between USPIOs is large enough to compete with thermal agitation energy and induce a phase separation between the quasi-spherical $\gamma-\mathrm{Fe}_{2} \mathrm{O}_{3}$ nanoparticles and the rod-like blocks of the copolymer. The same model can predict the maximum size 5 of spheres embedded in PBLG helical blocks that would not lead to phase separation, due to $U_{\text {depl }}(H=0)<k_{\mathrm{B}} T$ : we find $R_{\max }=2 \mathrm{~nm}$. Although this lower size would significantly decrease the properties of the USPIOs for MRI, it would be still interesting to use them in hybrids as $T_{1}$ contrasting agents instead of $T_{2}{ }^{33}$

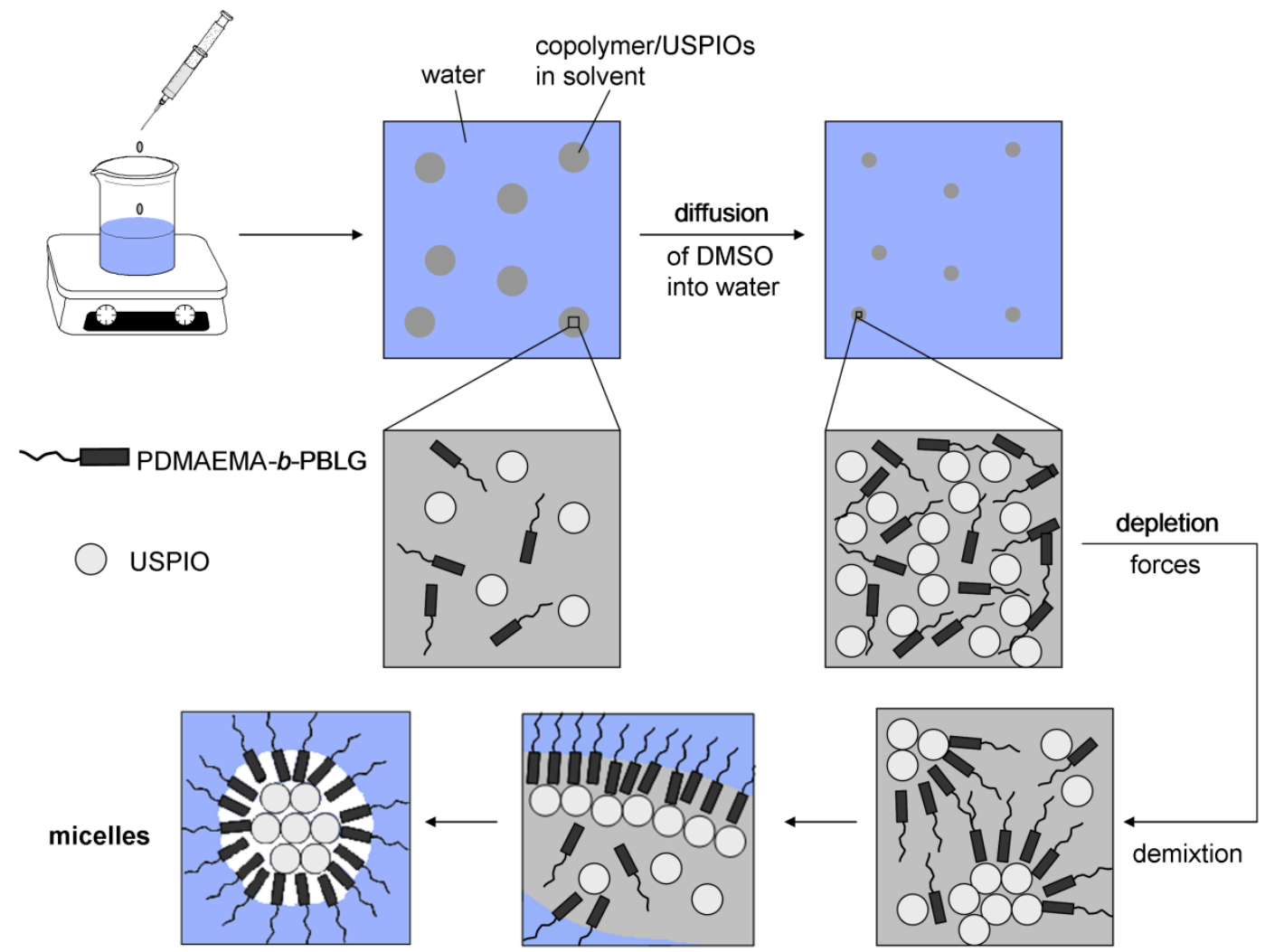

Fig. 7 Sketch of the micro-phase separation due to depletion attraction between USPIO spheres in PBLG rods leading to the vesicle-to-micelle transition.

The successive steps of the self-assembly of hydrophobically coated USPIOs and PDMAEMA $85-b-\mathrm{PBLG}_{41}$ is sketched on Fig. 15 7. When water is slowly added in the DMSO solution containing both the rod-coil copolymer and the quasi-spherical magnetic nanoparticles, the solvent quality decreases progressively for PBLG and the hydrophobically coated $\gamma-\mathrm{Fe}_{2} \mathrm{O}_{3}$ nanoparticles that concentrate in DMSO rich domains, increasing their local 20 concentration. At some point, when the solvent mixture becomes really poor, the system "precipitates" at a nanometric scale, leading to very high concentrations of the components locally. The depletion forces between $\gamma-\mathrm{Fe}_{2} \mathrm{O}_{3}$ spheres in PBLG rods are then so large within the hydrophobic cores that the binary system 25 demixes into internal domains. To explain the transition between the demixed droplet and the final cartoon, we invoke the spontaneous curvature of the USPIO favouring a core-shell micelle with the close-packed nanospheres in the core and expelling the rod-like copolymer at the interface with the 30 hydrophilic shell.

\section{Conclusions}

Colloidal suspensions are present in many synthetic materials, such as paints, glues, inks, and in biological components like cells, bacteria and viruses. In living systems, they exhibit 35 important transport and structural properties that mainly depend on the size, shape, concentration and composition. Depletion forces are playing an important role in the equilibrium phases of such complex systems, with an important contribution of the excluded-volume interaction to the free energy. We have 40 demonstrated here that the self-assembled structure of rod-coil amphiphilic diblock copolymers mixed with quasi-spherical nanoparticles is not only governed by their amphiphilic character, but also by excluded-volume interactions. This experimental demonstration opens an interesting route for the design of 45 complex and controlled assemblies of hybrid nanostructures using depletion effects combined to self-assembly. It is known that such entropic effects can produce crystal arrays of colloids, ${ }^{34}$ but also affect the function of a cell. ${ }^{35}$ This means that such forces are not only playing an important role in the structural and ${ }_{50}$ physical properties of such systems, but also in their functions.

\section{Notes and references}

${ }^{a}$ Université de Bordeaux/IPB, ENSCBP, 16 avenue Pey Berland, 33607 Pessac Cedex, France.

${ }^{b}$ CNRS, Laboratoire de Chimie des Polymères Organiques (UMR5629), 55 Pessac, France.

${ }^{c}$ CEA Saclay, LLB, 91191 Gif sur Yvette, France

${ }^{d}$ CNRS, Laboratoire Léon Brillouin (UMR12), Gif sur Yvette, France

*Correspondence to SL: E-mail: lecommandoux@enscbp.fr; Fax: +33 5 4000 8487; Tel: +3 54000 2241; and OS: E-mail: osandre@enscbp.fr; 60 Fax: +33 54000 8487; Tel: +3 54000 3695; 
$\dagger$ Electronic Supplementary Information (ESI) available: Fig. S1 Magnetization curve vs. applied magnetic field and distribution law of 5 diameters for the USPIOs dispersed in $\mathrm{CH}_{2} \mathrm{Cl}_{2}$. Fig. S2 DSC curves representing the heat flow $(\mathrm{mW} / \mathrm{g}) v s$. temperature $\left({ }^{\circ} \mathrm{C}\right)$ for the copolymer and the homopolymers. See DOI: 10.1039/C1SM05638G $\pm$

10

$$
K_{1}(0)=-\pi / 6(1+0.8762 L / R) /\left(1+1.33198 L / R+0.98225(L / R)^{2}\right.
$$

1 I. W. Hamley and V. Castelletto, Angew. Chem. Int. Ed. 2007, 46, 4442.

2 R. J. Ellis, Trends in Biochem. Sciences 2001, 26, 597; A.P. Minton, J. Biol. Chem. 2001, 276, 597; R. J. Ellis, Nature 2002, 416, 483; M. Kinoshita and T. Oguni, Chem. Phys. Lett. 2002, 351, 79

3 B. Götzelmann, R. Roth, S. Dietrich, M. Dijkstra and R. Evans, Europhys. Lett. 1999, 47, 398 ; R. Roth, R. Evans and S. Dietrich, Phys. Rev. E 2000, 62, 5360.

4 D. Rudhardt, C. Bechinger and P. Leiderer, Phys. Rev. Lett. 1998, 81, 1330 ; R. Verma, J. C. Crocker, T.C. Lubensky and A.G. Yodh, Phys. Rev. Lett. 1998, 81, 4004.

5 H. Bermudez, A. K. Brannan, D.A. Hammer, F. S. Bates and D. E. Discher, Macromolecules 2002, 35, 8203.

6 W. Agut, A. Brûlet, C. Schatz, D. Taton and S. Lecommandoux, Langmuir 2010, 26, 10546.

7 H. Schlaad, Adv. Polym. Sci. 2006, 202, 53; J. Rodriguez-Hernandez, S. Lecommandoux, J. Am. Chem. Soc. 2005, 127, 2026; E. P. Holowka, D. J. Pochan and T. J. Deming, J. Am. Chem. Soc. 2005, 127, 12423; E. G. Bellomo, M. D. Wyrsta, L. Pakstis, D. J. Pochan and T. J. Deming, Nat Mater 2004, 3, 244; A. Carlsen and S. Lecommandoux, Curr. Opin. Colloid Interface Sci. 2009, 14, 329.

8 S. Mornet, S. Vasseur, F. Grasset and E. Duguet, J. Mat. Chem. 2004, 14, 2161.

9 R. Weissleder, D. Stark, B. L. Engelstad, B. R. Bacon, C. C. Compton, D. L. White, P. Jacobs and J. Lewis, Am. J. Roentgenol. 1989, 152, 167.

10 H. Ai, C. Flask, B. Weinberg, X. T. Shuai, M. D. Pagel, D. Farrell, J. Duerk, J. Gao, Adv. Mat. 2005, 17, 1949; B.-S. Kim, J.-M. Qiu, J.-P. Wang and T. A. Taton, Nano Lett. 2005, 5, 1987.

11 J.-F. Berret, N. Schonbeck, F. Gazeau, D. El Kharrat, O. Sandre, A. Vacher and M. Airiau, J. Am. Chem. Soc. 2006, 128, 1755

12 C. Paquet, H. W. de Haan, D. M. Leek, H.-Y. Lin, B. Xiang, G. Tian, A. Kell and B. Simard, ACS Nano 2011, 5, doi: 10.1021/nn2002272.

13 S. Lecommandoux, O. Sandre, F. Chécot, J. Rodriguez-Hernandez, and R. Perzynski, Adv. Mat 2005, 17, 712; S. Lecommandoux, O. Sandre, F. Chécot, J. Rodriguez-Hernandez and R. Perzynski, J. Magn. Magn. Mater. 2006, 300, 71; S. Lecommandoux, O. Sandre, F. Checot and R. Perzynski, Progr. Sol. State Chem. 2006, 34, 171.

14 M. Krack, H. Hohenberg, A. Kornowski, P. Lindner, H. Weller and S. Förster, J. Am. Chem. Soc. 2008, 130, 7315.

15 R. J. Hickey, B. L. Sanchez-Gaytan, W. Cui, R. J. Composto, M. Fryd, B. B. Wayland and S.-J. Park, Small 2009, 6, 48; R. J. Hickey, A. S. Haynes, J. M. Kikkawa and S.-J. Park, J. Am. Chem. Soc. 2010, 133, 1517.

16 C. Sanson, O. Diou, J. Thévenot, E. Ibarboure, A. Soum, A. Brûlet, V. Dupuis, S. Miraux, E. Thiaudière, S. Tan, A. Brisson, O. Sandre and S. Lecommandoux, ACS Nano 2011, 5, 1122.

17 W. Agut, D. Taton and S. Lecommandoux, Macromolecules, 2007, 40, 5653 .

18 R. Massart, IEEE Trans. on Magnetics 1981, MAG-17, 1247.

19 R. Massart, E. Dubois, V. Cabuil, E. Hasmonay, J. Mag. Mag. Mat., 1995, 149, 1.

20 C. Da Cruz, O. Sandre, V. Cabuil, J. Phys. Chem. B 2005, 109, 14292.

21 C. Allen, D. Maysinger and A. Eisenberg, Colloids and Surf. B: Biointerfaces, 1999, 16, 3.

22 M. E. Yildiz, R. K. Prud'homme, I. Robb and D. H. Adamson, Polym. Adv. Technol., 2007, 18, 427.
23 J.-P. Cotton in Neutron, X-Ray and Light Scattering, P. Lindner, T. Zemb Ed., Elsevier, North-Holland, Delta series, 1991, chap. II, p.19.

24 H.-A. Klok, J. F. Langenwalter and S. Lecommandoux, Macromolecules 2000, 33, 7819; S. Lecommandoux, M.-F. Achard, J. F. Langenwalter and H.-A. Klok, Macromolecules 2001, 34, 9100.

25 F. Sanda, G. Gao and T. Masuda, Macromol. Bioscience 2004, 4, 570.

26 C. Sanson, C. Schatz, J.-F. Le Meins, A. Brûlet, A. Soum and S. Lecommandoux, Langmuir 2010, 26, 2751

27 J. S. Pedersen, Adv. in Coll. and Interf. Sci. 1997, 70, 171.

28 S. M. Yu, V. P. Conticello, G. Zhang, C. Kayser, M. J. Fournier, T. L. Mason and D. A. Tirrell, Nature, 1997, 389, 167.

29 A. O. Moughton and R. K. O’Reilly, Chem. Commun. 2010, 46, 1091.

30 J. S. Crespo, S. Lecommandoux, R. Borsali, H.-A. Klok and V. Soldi, Macromolecules 2003, 36, 1253.

31 M. Adams, Z. Dogic, S. L. Keller and S. Fraden, Nature, 1997, 393, 349; G.A. Vliegenthart and H.N.W. Lekkerkerker, J. Chem. Phys. 1999, 111, 4153.

32 K. Yaman, C. Jeppesen and C. M. Marques, Europhys. Lett., 1998, 42, 221.

33 U. I. Tromsdorf, O. T. Bruns, S. C. Salmen, U. Beisiegel and H. Weller, Nano Lett. 2009, 9, 4434.

34 A. D. Dinsmore and A. G. Yodh, Langmuir 1998, 15, 314

35 R. Roth, B. Götzelmann and S. Dietrich, Phys. Rev. Lett. 1999, 83, 448. 